\title{
Analyzing Manpower Data of Higher Learning Institutions: A Markov Chain Approach
}

\author{
Rahela Abdul Rahim \\ School Of Quantitative Sciences, University Utara Malaysia \\ Sintok, Kedah, Malaysia \\ Email: rahela@uum.edu.my
}

Doi:10.5296/ijhrs.v5i3.7969 URL: http://dx.doi.org/10.5296/ijhrs.v5i3.7969

\begin{abstract}
The approach to manpower policy in most Malaysian universities appears to be guided by the traditional method of putting the right number of people in the right place at the right time or arranging for suitable number of people to be allocated to various jobs usually in a hierarchical structure. The technique has been practiced for years. This traditional method is deficit in the sense that it neither offers computational tools that will enable administrators to determine possible line of action to be taken nor provide tools to generate alternative policies and strategies. The objective of this study was to design a planning model for projecting university faculty employment under alternative policy suggested by the government. The planning model was developed using Markov chain technique. Two scenarios were considered in the study; scenario 1 was based on historical data pattern between year 1999 2014 and scenario 2 was based on RMK 9 policies. The results showed the possibility average length of stay by position and probability of loss for both scenarios. The greater impact is expected for average length of stay of senior lecturers compared to other faculty position considering the new policy.
\end{abstract}

Keywords: Markov chain, Manpower flow, Faculty flow 


\section{Introduction}

Year 2015 providing an apt background for higher learning institution to reinvent their academic staff or faculty appointment policy. The first mission stated by MOHE (Ministry of Higher Education) is to create a strategic and systematic plan for higher education. With 900,000 students pursuing higher education in 20 public universities, 33 private universities and university colleges, 4 foreign university branch campuses, 22 polytechnics, 37 community colleges and about 500 private colleges (Source: MOHE), it is the responsibility of each institution to remain its competitiveness. The management of the learning institution should be able to manage all the important elements that serve as the catalyst for the institutional development.

Obviously manpower is one of the crucial factor in achieving the mission and also an aid to the institutional planning process.. Earliest manpower analysis models in higher learning institutions were developed in Berkeley campus of University California (Bleau, 1982). The analysis contributes issues of staff recruitment, retirement, and retention towards improving recruitment success, faculty retention, and better planning for future campus faculty hiring needs. By understanding the manpower behaviour, management of the university can make a plan for the future. Central aspect of manpower planning problems lays in lecturers' shortages (Montgomery, et al., 1999; Bleau, 1982). These shortages are reasoned by no commensurate of supply and demand of lecturers as it comes from poor recruitment by management in flow of lecturers in faculty.

Manpower planning in Higher learning institution in Malaysia has been an important issue especially in management. Basically the manpower planning analysis has been done using management approach. Other study on manpower planning in Malaysia is health manpower forecasting in Malaysia (Bleau, 1982). To meet the demand for higher education and to stem the outflow of foreign exchange, the government during the Sixth Malaysian Plan, 1991-1995, adopted a policy of expanding the role of the private sector as a provider of higher education. This was within the wider policy framework of promoting the private sector as a provider of higher education (Sivalingam, 2006). Because of this policy, more private universities appear and has become competitors to the public universities. Interesting offers from private universities and business organization attract more lecturers to resign from public universities. If careful attention is not given to forecast the impact of this scenario, public higher learning institution will face problem in recruiting and maintaining their academic staff of good quality. Indirectly this will influence their student's academic performance.

Based on the existing scenario, especially in the Malaysian context, some of the academic flow related questions decision makers must think of in long term planning of the institution are;

a) What will the academic staff demographics such as rank mix, look like in the long term.

b) What will the average length of stay of academic status look like in the long term if the current appointment policy is maintained? If it is changed? 


\section{Macrothink}

International Journal of Human Resource Studies

ISSN 2162-3058

2015, Vol. 5, No. 3

Academic flow modeling can help answer these questions quickly. Once the questions have been answered, they will be used for faculty planning. Government has also considered an effort to improve the faculty employment in the public universities by introducing a new policy in RMK-9 (Malaysia $9^{\text {th }}$ Planning) policies. The new policy stated that in the RMK-9, the status rank of lecturer should be decreased by $10 \%$ while senior lecturers and associate professors should be increased by $70 \%$. The question arise here was whether the new policy will have an impact on the distribution number of faculty with diverse status rank as compared to the present policy.

\section{Model Development}

To model the flow of manpower through an institution as a Markov chain model, one must define the stage interval and states, collect data, estimate the transition probability matrix (TPM) and validate the model. The first step in model development is the decision on what stage interval (time period) to use, for example weekly, monthly, yearly, etc. A small time interval will probably produce accurate estimates of TPM but a constant TPM will be less favorable. The model developed may turn out to be quite good, while another quite poor, therefore the validation of the model is necessary so that the model could be used for forecasting and analysis. In general the choice of stage interval should be guided by the planning decision and objectives of the study. Since the objective of this study is to analyse the time frame for faculty promotion, a five year period is used as the time interval. We feel this is the reasonable time frame for promotion and quite a common experience among the faculties.

The second steps in Markov chain modeling is the selection of non-overlapping states to which a faculty can be classified. The number of states should be determined carefully. The number of states should not be too small nor too big to avoid the confounding effect and may cause the poor estimate of TPM. In a graded faculty system, the states can be physically defined by position level which is non-absorbing states. Table 1 shows the TPM calculated from year 2000-2005 transition data. There are 8 non absorbing states by position levels. From personnel history data, the 5 year transitions by state were tabulated manually. One difficulty in data collection is every individual record has to be examined. The limitation can be minimized if a computerized database that could extract necessary individual information is realized. But currently that system is not yet possible.

Having counted the total number of individual transition in 5 years, TPM can be easily estimated by converting entries to row proportion as shown in Table 1. 
Table 1.Faculty Transition Probability Matrix

\begin{tabular}{|c|c|c|c|c|c|c|c|c|}
\hline & Quit & Retire & Absent: & $\mathrm{T}$ & $\mathrm{L}$ & SL & AP & $\mathrm{P}$ \\
\hline & & & $\begin{array}{l}\text { with } \\
\text { leave }\end{array}$ & & & & & \\
\hline $\mathrm{T}$ & 0.0116 & 0 & 0.0224 & 0.8926 & 0.07346 & - & - & - \\
\hline $\mathrm{L}$ & 0.0072 & 0.0050 & 0.0110 & - & 0.8889 & 0.0879 & - & - \\
\hline SL & 0.0162 & 0.0032 & 0.0034 & - & - & 0.8526 & 0.1407 & - \\
\hline AP & 0.0132 & 0.0026 & 0.0014 & - & - & - & 0.8421 & 0.1407 \\
\hline $\mathrm{P}$ & 0.0006 & 0.0012 & 0.0008 & - & - & - & - & 0.9974 \\
\hline \multicolumn{9}{|c|}{ FROM } \\
\hline $\mathrm{C}$ & - & - & - & 0.0642 & 0.7742 & 0.1616 & 0 & 0 \\
\hline $\mathrm{SC}$ & - & - & - & - & - & - & 0.4624 & 0.5376 \\
\hline V & - & - & - & - & - & - & 0.5840 & 0.4160 \\
\hline
\end{tabular}

Symbols used:

- Transition is not possible

Type of Faculty by position in the Higher Learning Institutions

T Tutor

L Lecturer

SL Senior Lecturer

AP Associate Professor

P Professor 


\section{Macrothink}

Types of Gains

C Contract

SC Seconmend

V Visiting

\section{Types of Loss}

Q Quit

Retire

Absence with leave

$\mathrm{T}$ : number of time periods observed

$s_{i j}(t)$ : number of faculties that moved from state $i$ to $j$ during period $t$

Therefore

$s_{i j}(t)=\sum_{j=1}^{p} s_{i j}(t)$ is the total number of faculties available in state $i$ at the beginning of period $t$;

$p_{i j}=\frac{s_{i j}(t)}{s_{i}(t)} \quad$ the proportion of people that moved from state I to state $\mathrm{j}$ during period $\mathrm{t}$

\section{Method}

For this study, one university in Malaysia was selected as the case study. At present, the university consists of three colleges which are the College of Arts and Sciences, College of Business and College of Laws, Government and International Studies. There are more than 1000 academic professions with different academic rank; assistant professors, senior lecturers and lecturers with variety of age range from 22 years old until 61 years old. The sources of secondary data for this research were obtained from the Department of Registrar of that university for 5 years which was from 1999 until 2014. The basis of Markov chain model is a matrix where each row and column corresponds to a current faculty status states (e.g position level). The cell in the matrix indicates the probabilities of which the faculty members move to different states. Transition probabilities were calculated based on the data range of 10 years indicates the movement of each faculty member into, through or out of a given state. The model used the actual distribution of the university faculty members in year 1999-2014 as a beginning and developed projection for the respective state using the initial transition probability matrix or the matrix is adjusted for possible academic personnel policy changes. The model was developed as a finite Markov chain using Microsoft Excel. A finite Markov chain displays a finite number of states with its transition matrix consist of the probability the faculty member will stay in the state or move to another state. The probability was based on the historical data, representing different position level of faculty. The initial transition probability matrix for year 1999-2014 was used to multiply with initial matrix transition diagram to predict the future transitions of academic faculty. Differences between the actual and projected numbers of faculty members were tested by comparing the projected number of faculty members in 2015 with the observed number of faculty members in 2015. This validation was done using chi-square goodness of fit test. 


\section{Al Macrothink}

International Journal of Human Resource Studies

ISSN 2162-3058

2015, Vol. 5, No. 3

The step followed after the initial model was developed and tested was to set the alternative scenarios for analysis. The 1999-2014 year data were used for initial faculty distribution and was used to project to the year 2015-2019. Two alternative scenarios were proposed in this study. The first scenario considers the policy of promoting the academic staff remain the same as in year 1999-2014 Therefore the transition probabilities developed from the previous five years of data would hold. The second scenario considered the new policy suggested by the government that the appointment of lecturer should be decreased by $10 \%$ while senior lecturers and associate professors should be increased by $70 \%$. In this model the transition probabilities would change according to the respective change in the number of academic staff appointed.

\section{Results and Analysis}

Matrix transition probability for data distribution of year 1999-2014 was used to project faculty distribution. The assumption was the historical patterns for 1999-2014 will continue if policy of faculty appointment remains the same. The transition probability matrix (Table 2) indicates the probability that a faculty will move from one state to another within one period (5 years). For example the probability of remaining in the same position increases with seniority from 2.9154 (Tutor) to 6.7842 (Senior Lecturer) and slightly decrease from 6.3331(Associate Professor) to 4.2626 (Professor). Table 3 provides the average length of stay for each level of position. The important use of Markov Chain is to predict future manpower distributions if there is policy changes in the current policy. As stated earlier, regarding the RMK9 policies, which is the recruitments of tutor and lecturer will be reduced by $10 \%$ and the appointment of senior lecturer, associate professor and professor will be increased by $70 \%$, a new formation of matrix transition diagram is realized. We consider this policy change as scenario 2 and the old policy as scenario 1 .

Table 2. 2015-2020 Predictions By Levels - Years Of Average Stay

\begin{tabular}{|l|l|l|l|l|l|l|l|l|}
\hline & T & L & SL & AP & P & C & SC & VIS \\
\hline T & 2.9154 & 0.9075 & 0.5412 & 0.4380 & 0.2627 & - & - & - \\
\hline L & & 4.241 & 2.529 & 2.0469 & 1.2276 & - & - & - \\
\hline SL & & & 6.7842 & 5.4910 & 3.2932 & - & - & - \\
\hline AP & & & & 6.3331 & 3.7982 & - & - & - \\
\hline $\mathrm{P}$ & & & & - & 4.2626 & - & - & - \\
\hline $\mathrm{C}$ & 1.7694 & 1.7439 & 1.7982 & 1.4554 & 0.8729 & 1.7409 & - & - \\
\hline
\end{tabular}




\begin{tabular}{|l|l|l|l|l|l|l|l|l|}
\hline SC & - & - & - & 4.0011 & 3.9692 & - & 1.3363 & - \\
\hline VIS & - & - & - & 4.9966 & 3.8963 & - & - & 1.3510 \\
\hline & & & & & & & & \\
V & - & - & - & - & - & - & 0.5840 & 0.4160 \\
\hline
\end{tabular}

Table 3. 2015-2020 Prediction By Levels - Average Length of Stay Scenario 1.

\begin{tabular}{lllllllll}
\hline ENTRY & $\mathrm{T}$ & $\mathrm{L}$ & $\mathrm{SL}$ & $\mathrm{AP}$ & $\mathrm{P}$ & $\mathrm{C}$ & $\mathrm{SC}$ & \multicolumn{2}{l}{ VIS } \\
\hline YEARS & 2.5325 & 5.0222 & 7.7842 & 5.0657 & 2.1313 & 4.6904 & 4.6683 & 5.1219 \\
\hline
\end{tabular}

Table 4. 2015-2020 Prediction by Levels - Average Length of Stay Scenario 2.

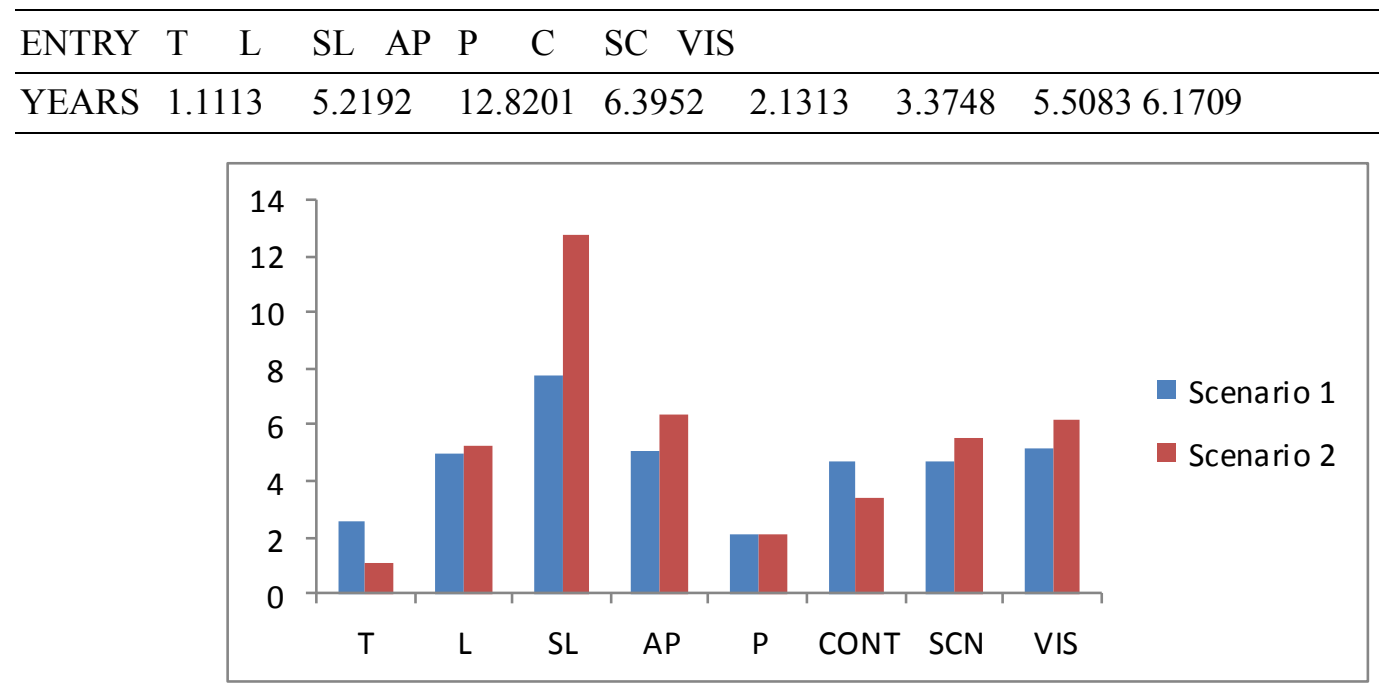

Figure1. Comparative Average Length of Stay by Levels.

Average length of stay for tutors is expected to decrease in scenario 2 and a slight increase for the lecturers as shown in Figure 1. Obviously, the increased in the average length of stay is seen for senior lecturer and slightly increased for Associate Professor, while the prediction for average length of stay remains for the Professors. 
Table5. 2015-2020 Predictions Probability of Loss By Levels.

\begin{tabular}{|l|l|l|l|}
\hline & Quit & Retire & $\begin{array}{l}\text { Absent } \\
\text { With } \\
\text { Leave }\end{array}$ \\
\hline T & 0.0551 & 0.0077 & 0.0779 \\
\hline L & 0.0993 & 0.0361 & 0.0591 \\
\hline SL & 0.1844 & 0.0399 & 0.0333 \\
\hline AP & 0.0859 & 0.0210 & 0.0119 \\
\hline P & 0.0026 & 0.0051 & 0.0034 \\
\hline
\end{tabular}

Table 6. 2015-2020 Predictions Probability of Loss by Levels.

\begin{tabular}{|l|l|l|l|}
\hline & Quit & Retire & $\begin{array}{l}\text { Absent } \\
\text { With } \\
\text { Leave }\end{array}$ \\
\hline $\mathrm{T}$ & 0.0551 & 0.0077 & 0.0779 \\
\hline $\mathrm{L}$ & 0.0993 & 0.0361 & 0.0591 \\
\hline $\mathrm{SL}$ & 0.1844 & 0.0399 & 0.0333 \\
\hline $\mathrm{AP}$ & 0.0859 & 0.0210 & 0.0119 \\
\hline $\mathrm{P}$ & 0.0026 & 0.0051 & 0.0034 \\
\hline
\end{tabular}


Table 7. 2015-2020 Predictions Probability of Loss by Levels Scenario 2.

\begin{tabular}{|l|l|l|l|}
\hline & Quit & Retire & $\begin{array}{l}\text { Absent } \\
\text { With } \\
\text { Leave }\end{array}$ \\
\hline $\mathrm{T}$ & 0.0128 & 0.0001 & 0.0241 \\
\hline $\mathrm{L}$ & 0.0463 & 0.0147 & 0.0189 \\
\hline $\mathrm{SL}$ & 0.2386 & 0.0574 & 0.0438 \\
\hline $\mathrm{P}$ & 0.0026 & 0.0051 & 0.0034 \\
\hline
\end{tabular}

The probability of loss has increased for some position. For example from 0.1844 to 0.2386 for senior lecturers, while the loss has decreased for lower position and the loss remain about the same value for higher position.

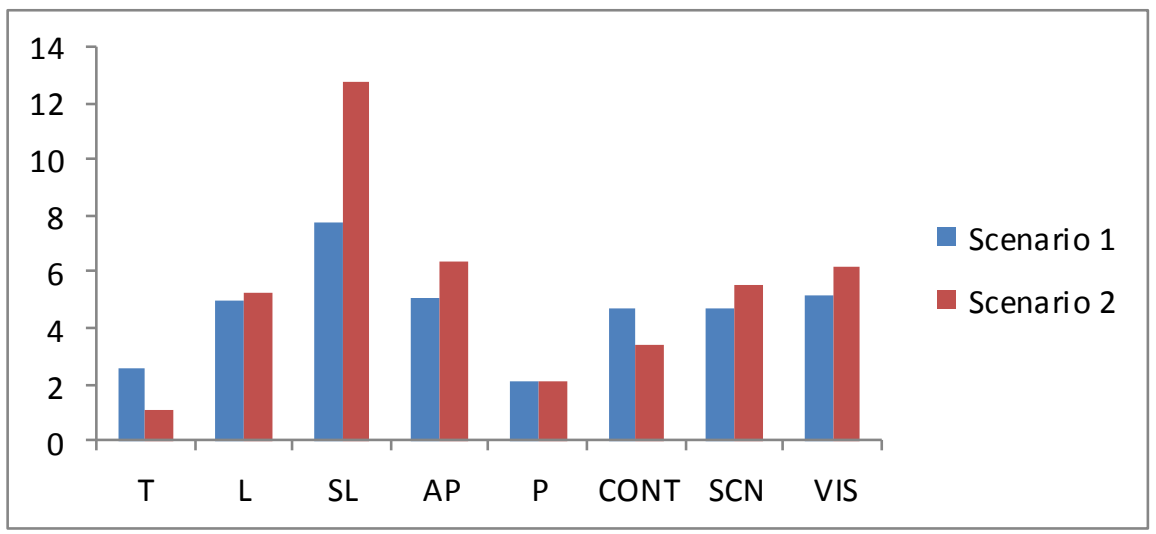

Figure 2.Comparative Average Length of Stay by Levels

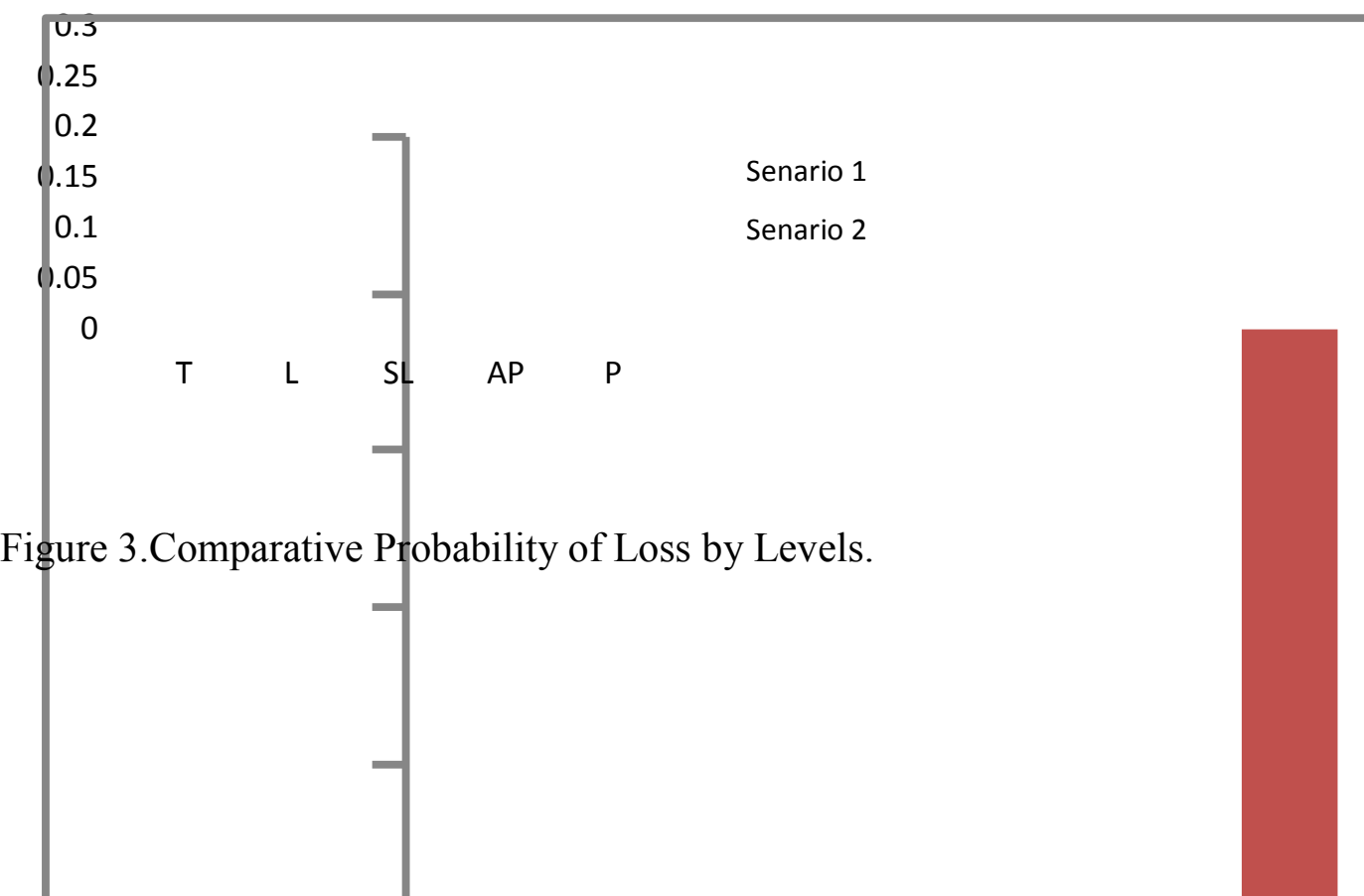




\section{Macrothink}

International Journal of Human Resource Studies

ISSN 2162-3058

2015, Vol. 5, No. 3

Predictions for each of these scenarios indicate changes of the trend seen between 2015 and 2020 towards more senior faculty members. This exercise demonstrates that if new policy as suggested by the government were imposed, there is an accompanying impact on the average length of stay and probability of loss of faculty members. The impact can be seen among senior lecturers. Although both scenarios in this study were relatively simple for model evaluation, the output can help administrators to plan ahead. Beyond needs of the budget, an ideal mix of young lecturers and senior lecturers require wise consideration.

\section{Conclusion}

Based on the results obtained, the Markov chain model developed in this study is an appropriate evaluation tool for policy change concerning the appointment of faculty. This paper demonstrates that if new policy is implemented, there will be a high impact on the number of academic staff by diverse rank especially towards more senior faculty members. However mean time for the faculties remain in current state does not show much difference between old and new policy.

\section{Acknowledgement}

First and foremost, we would like to extend our sincere thanks to Ministry of Science, Technology and Innovation, and UUM for providing this research grant (s/o code: 12905)

\section{References}

Aulia, D. and Ayu, S. F. (2010). Health Manpower Forecasting in Malaysia, Masters Thesis, University Kebangsaan Malaysia.

Bleau, B.L. (1982). Faculty Planning Models: A Review of the Literature, The Journal of Higher Education, 53(2), 195-206.

Montgomery,B.A., Lloyd, J.W., and Jensen, A. (1999), Use of a Markov-Chain Model to Evaluate Employment Policies for a Veterinary School Faculty, Journal of Veterinary Medical Education, 21(1), 56 - 67.

Sivalingam, G. (2006). Privatisation of Higher Education in Malaysia. Forum on Public Policy.

\section{Copyright Disclaimer}

Copyright for this article is retained by the author(s), with first publication rights granted to the journal.

This is an open-access article distributed under the terms and conditions of the Creative Commons Attribution license (http://creativecommons.org/licenses/by/3.0/). 